\title{
Malaysian wooden furniture industry : study of safety standards, compliance and consequential implications.
}

\begin{abstract}
The improvement of health and safety standards within the organisational context is an important issue of global concern. The traditional approach to managing workplace safety in Malaysia has focused on the technical aspects of engineering systems and processes, and it has attributed the majority of workplace accidents and injuries to unsafe working conditions instead of the unsafe work practices of employees. However, there has been a fundamental shift in the safety management research carried out in many countries and across diverse industries, which aims to measure the impact of attitudinal, organisational, cultural and social dimensions on occupational safety. The factors affecting the safety level in the Malaysian wooden furniture industry was studied in 30 wooden furniture manufacturing factories, using a structured questionnaire. The study found that although there were four determinants of the prevailing safety climate in the work environment, it was the management responsibility and safety precautions that had the strongest influence on safety climate. Further, the primary health and safety concerns among workers in the wooden furniture manufacturing industry were the air-borne dust, noise, chemical exposure, materials handling and occupational accidents. In this context, it is essential for the management to show commitment towards health and safety and incorporate safety precautions into the operational system, to ensure a safe working environment in the wooden furniture manufacturing industry. Further, in order to improve the safety level within the wooden furniture industry, the economics and policies that govern the implementation of safety and health precautions must be emphasised, as the wooden furniture industry is a cost sensitive industry.
\end{abstract}

Keyword: Safety climate; Safety precautions; Safety practices; Safe work environment; Wooden furniture industry. 